\title{
Effect of Shenmai injection on cognitive function after cardiopulmonary bypass in cardiac surgical patients: a randomized controlled trial
}

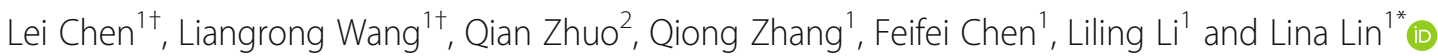

\begin{abstract}
Background: Postoperative cognitive dysfunction (POCD) is a common complication after cardiac surgery that influences the clinical outcomes and quality of life of patients. This study aimed to evaluate the effects of Shenmai injection (SMI) on POCD of patients who underwent cardiac valve replacement under cardiopulmonary bypass (CPB).

Methods: This prospective, randomized, controlled trial was conducted from September 2014 to January 2017. Eightyeight patients receiving cardiac valve replacement under CPB were randomized into the control (C) or the SMI (S) group. SMI $(0.6 \mathrm{~mL} / \mathrm{kg})$ was administered intravenously from the time of anesthesia induction to the beginning of CPB. Cognitive function was assessed at 3 days before surgery and 3 days, 7 days, and 1 month after surgery using the Beijing version of the Montreal Cognitive Assessment (MoCA-BJ) score. The serum levels of neuroglobin (Ngb), hypoxiainducible factor-1a (HIF-1a), and neuron-specific enolase (NSE) were measured at $30 \mathrm{~min}$ after induction $\left(\mathrm{T}_{0}\right)$, immediately after the endonasal temperature rewarmed to $36^{\circ} \mathrm{C}\left(T_{1}\right)$, and $1 \mathrm{~h}\left(\mathrm{~T}_{2}\right), 6 \mathrm{~h}\left(\mathrm{~T}_{3}\right), 24 \mathrm{~h}\left(\mathrm{~T}_{4}\right), 48 \mathrm{~h}\left(\mathrm{~T}_{5}\right)$, and $72 \mathrm{~h}$ $\left(T_{6}\right)$ after $C P B$.

Results: Compared with the baseline values at $T_{0}$, the serum Ngb levels in group $C$ were significantly decreased at $T_{1-2}$ and then increased at $T_{3-6}$, while the levels in group $S$ were decreased at $T_{1-2}$ and increased at $T_{4-6}$, compared to group C $(p<0.05)$. The serum HIF-1a levels at $T_{1-4}$ and the serum NSE levels at $T_{1-6}$ were significantly increased in both groups $(p<0.05)$. The serum levels of Ngb at $T_{3}, H I F-1 a$ at $T_{1-3,}$, and NSE at $T_{3-4,6}$ were lower in group $S_{\text {, compared to }}$ group $C(p<0.01)$. The MoCA-BJ scores were decreased at 3 and 7 days after surgery in both groups, and the MoCA-BJ scores in group $S$ were higher than those in group $C$ at 3 and 7 days after surgery $(p<0.01)$.
\end{abstract}

Conclusion: Cognitive function is impaired postoperatively in patients who have undergone cardiac valve replacement under CPB. In addition, treatment with the traditional Chinese medicine SMI decreases the serum levels of Ngb, HIF-1a, and NSE as well as attenuates cognitive dysfunction.

Trial registration: This trial was registered with Clinicaltrials.gov as ChiCTR-TRC-14004373 on March 11, 2014.

Keywords: Cardiopulmonary bypass, Cognitive dysfunction, Shenmai injection, Cerebral protection

\footnotetext{
* Correspondence: luckstone009@163.com

${ }^{\dagger}$ Lei Chen and Liangrong Wang contributed equally to this work.

'Department of Anesthesiology, The First Affiliated Hospital of Wenzhou

Medical University, Wenzhou, Zhejiang Province, China

Full list of author information is available at the end of the article
}

(c) The Author(s). 2018 Open Access This article is distributed under the terms of the Creative Commons Attribution 4.0 International License (http://creativecommons.org/licenses/by/4.0/), which permits unrestricted use, distribution, and reproduction in any medium, provided you give appropriate credit to the original author(s) and the source, provide a link to the Creative Commons license, and indicate if changes were made. The Creative Commons Public Domain Dedication waiver (http://creativecommons.org/publicdomain/zero/1.0/) applies to the data made available in this article, unless otherwise stated. 


\section{Background}

Postoperative cognitive dysfunction (POCD) is considered as a common complication of cardiovascular surgery and causes several adverse effects, such as a delayed long-term recovery, a reduced quality of life, and an increased mortality rate [1,2]. Cerebral embolization, systemic inflammatory response, and low cerebral oxygenation to cerebral hypoperfusion are usually implicated as potential factors for short-term POCD after cardiac surgery [3, 4]. In addition, oxygenation and upregulation of neuroglobin $(\mathrm{Ngb})$ and hypoxia-inducible factor- $1 \alpha$ (HIF- $1 \alpha)$ expression have been considered as a protective mechanism responding to ischemic injury to neurons, while neuron-specific enolase (NSE) is a marker of neuronal damage. Therefore, the circulating levels of Ngb, HIF- $1 \alpha$, and NSE have been used as indicators for cerebral injury $[5,6]$. However, whether circulating Ngb, HIF-1 $\alpha$, and NSE levels could serve as early indicators for cognitive dysfunction after cardiac surgery has not been reported.

With the increasing understanding of the mechanisms involved, various treatments have been introduced over the last decade. Shenmai injection (SMI), a Chinese traditional medicine mainly consisting of the two herbal components Radix ginseng Rubra and Radix ophiopogonis, is extensively used in China as an organ protector [7]. Our previous studies [7-10] have demonstrated the protective effects of SMI against oxidative injury and the inflammatory response, showing its potential as a therapeutic agent for the prevention of lung injury after cardiopulmonary bypass (CPB). However, reports concerning the effects of SMI on cognitive function in patients undergoing cardiac valve replacement under $\mathrm{CPB}$ are not available.

Therefore, this prospective, randomized, controlled trial was designed to evaluate the predictive effects of serum Ngb, HIF- $1 \alpha$, and NSE on POCD after CPB as well as the protective effect provided by SMI administration in patients undergoing cardiac valve replacement under $\mathrm{CPB}$. The Beijing version of the Montreal Cognitive Assessment (MoCA-BJ; range, 0-30) was analyzed for assessing the cognitive function; and blood gas parameters of the jugular veins as well as Ngb, HIF- $1 \alpha$, and NSE expression levels were used to evaluate cerebral injury.

\section{Methods}

\section{Study design and patients}

This prospective, randomized, controlled trial was conducted from September 2014 to January 2017 at the First Affiliated Hospital of Wenzhou Medical University. This trial was registered with Clinicaltrials.gov as ChiCTRTRC-14004373 on March 11, 2014. After approval by the hospital's Clinical Research Ethics Committee and written informed consent from the patients, 90 patients receiving cardiac valve replacement under $\mathrm{CPB}$ were screened. This study was reported according to the CONSORT Extension for Chinese Herbal Medicine Formulas 2017: Recommendations, Explanation, and Elaboration checklist [11].

Inclusion criteria included American Society of Anesthesiologists physical status II-III, aged 40-69 years old, body mass index of $18-29 \mathrm{~kg} / \mathrm{m}^{2}$, left ventricular ejection fraction $\geq 0.3$, and preoperative MoCA-BJ score $\geq 26$. Patients were excluded from this study if they had a diagnosis of diabetes mellitus, hypertension, peripheral vascular disease, pulmonary disease, neurological disease, mental disorder, renal insufficiency, liver dysfunction, infective endocarditis, or previous coronary heart disease before screening. In addition, patients who received SMI treatment within 6 months were also excluded.

\section{Surgical interventions}

At $30 \mathrm{~min}$ before surgery, $0.2 \mathrm{mg} / \mathrm{kg}$ morphine and $0.3 \mathrm{mg} / \mathrm{kg}$ scopolamine were given intramuscularly. After a standard monitor was attached, a peripheral venous access was secured. Before induction, a 20-G arterial catheter was cannulated, and the sensor/transducer (FloTrac) was connected to record the waveform. Anesthesia was induced intravenously with $0.01 \mathrm{mg} / \mathrm{kg}$ midazolam, $0.6 \mu \mathrm{g} / \mathrm{kg}$ sufentanil, $0.3 \mathrm{mg} / \mathrm{kg}$ etomidate, and $0.15 \mathrm{mg} /$ $\mathrm{kg}$ vecuronium bromide, and then tracheal intubation was facilitated. The patients received intermittent positive-pressure ventilation with a tidal volume of 8 $10 \mathrm{~mL} / \mathrm{kg}$ and a respiratory rate of 10 beats per min to maintain the end-tidal carbon dioxide pressure at approximately $35 \mathrm{mmHg}$. Continuous administration of sevoflurane and propofol combined with intermittent injection of sufentanil and vecuronium were used to maintain the depth of anesthesia, which was monitored by the bispectral index. After anesthesia, the right internal jugular vein was reversely cannulated to the bulbar level for continuous blood sampling.

All patients received standard $\mathrm{CPB}$ management. $\mathrm{CPB}$ was instituted with a membrane oxygenator. The body temperature was maintained under mild hypothermia $\left(32-33{ }^{\circ} \mathrm{C}\right)$, and $\alpha$-stat was used for acid-base management. The pump flow was maintained at a rate of 2.0 $2.5 \mathrm{~L} / \mathrm{min} / \mathrm{m}^{2}$ using a nonpulsatile flow, and a blood cardioplegic solution was used. During the perioperative period including $\mathrm{CPB}$, the mean arterial blood pressure was maintained at $55-80 \mathrm{mmHg}$ using norepinephrine or vasopressin. Milrinone was used if the left ventricular ejection fraction was less than $30 \%$ after CPB, as measured by transesophageal echocardiography, in case of right ventricular dysfunction or pulmonary hypertension. A blood transfusion was needed if the hematocrit level fell below 21\% during CPB or below 25\% during the remaining perioperative period. Fresh frozen plasma was 
transfused when the international normalized ratio was greater than 1.5 with excessive bleeding greater than $200 \mathrm{~mL} / \mathrm{h}$ for two consecutive hours in the postoperative period. Platelet concentrates were transfused when the platelet count was less than $50,000 / \mathrm{mm}^{3}$ with excessive bleeding greater than $200 \mathrm{~mL} / \mathrm{h}$ for two consecutive hours in the postoperative period. All patients were transferred to the Coronary Care Unit (CCU) after surgery and received standard management according to institutional guidelines by the CCU staff.

\section{SMI administration}

SMI composed of Radix ginseng Rubra and Radix Ophiopogonis was a product of Sanjiu Pharmaceutical Co. Ltd. (Yaan, China; batch No. Z51021845, provided as $1 \mathrm{~g}$ of crude drug in an ampoule of $10 \mathrm{~mL}$ ). In group S, SMI at a dose of $0.6 \mathrm{~mL} / \mathrm{kg}$, dissolved in $250 \mathrm{~mL}$ of normal saline, was administered intravenously from the time of anesthesia induction to the beginning of $\mathrm{CPB}$ at a rate of $10 \mathrm{~mL} / \mathrm{min}$. The control patients were given an equal volume of normal saline instead.

\section{Outcome measures}

The durations of aortic cross clamping, $\mathrm{CPB}$, and anesthesia maintenance were recorded, respectively. The hemodynamic parameters, including the mean arterial blood pressure and heart rate, as well as the blood gas parameters of the jugular veins, which included the jugular venous oxygen saturation $\left(\mathrm{S}_{\mathrm{V}} \mathrm{VO}_{2}\right)$, jugular venous oxygen partial pressure $\left(\mathrm{P}_{\mathrm{J}} \mathrm{vO}\right)$, hemoglobin, hematocrit, and lactic acid (Lacjv) of the jugular venous blood samples, were collected at $30 \mathrm{~min}$ after induction $\left(\mathrm{T}_{0}\right)$, immediately after the endonasal temperature rewarmed to $36{ }^{\circ} \mathrm{C}\left(\mathrm{T}_{1}\right)$, the end of cardiac surgery $\left(\mathrm{T}_{2}\right)$, and $6 \mathrm{~h}$ $\left(\mathrm{T}_{3}\right), 24 \mathrm{~h}\left(\mathrm{~T}_{4}\right), 48 \mathrm{~h}\left(\mathrm{~T}_{5}\right)$, and $72 \mathrm{~h}\left(\mathrm{~T}_{6}\right)$ after $\mathrm{CPB}$, respectively. The MoCA-BJ scores were evaluated at 3 days before surgery as well as 3 days, 7 days, and 1 month after surgery.

The remaining blood sample was centrifuged to separate the serum, which was then stored at $-20{ }^{\circ} \mathrm{C}$ for subsequent analyses of Ngb, HIF- $1 \alpha$, and NSE. Indicators were determined using commercially available enzyme-linked immunosorbent assay kits (Westang Biotechnology Co. Ltd., Shanghai, China), according to the manufacturer's instructions. The levels of these indicators were measured by investigators unaware of the group allocation and the blood gas results.

\section{Sample size calculation and randomization}

The sample size was planned and calculated according to comparison of the MoCA-BJ on the third and seventh day postsurgery. With a power of $66 \%$ and a significance level of $5 \%$, a total of 17 patients would be required in each group to make a difference of -3.4 in the
MoCA-BJ on the third day postsurgery, with a dropout rate of $10 \%$. With a power of $31 \%$ and a significance level of 5\%, a total of 28 patients would be required in each group to make a difference of -1.7 in the MoCA-BJ on the seventh day postsurgery, with a dropout rate of $10 \%$. Thus, enrollment of 88 patients was planned to minimize statistical errors.

Patients were randomized using a sealed envelope system. Eighty-eight patients were randomized to either the SMI (group S, 44 cases) or the control (group C, 44 cases) group. The medical staff collecting and analyzing the MoCA-BJ scores was blinded to the treatment allocation.

\section{Statistical analysis}

Data were tested for normal distribution using the Kolmogorov-Smirnov test. Continuous, normally distributed data were expressed as the mean \pm standard deviation. Categorical data were expressed as numbers. Data on the block level were expressed as a median (range) and analyzed with the Mann-Whitney test. For comparison of demographic and operative data, categorical data were compared with the $x^{2}$ test and quantitative data were compared with the Student's t-test. For comparison of outcomes within the same group at different time points, data were analyzed by repeated-measures analysis of variance using the Bonferroni method. For comparison of outcomes between different groups at the same time point, the paired t-test was conducted. A $P$ value $<0.05$ was considered significant. Analysis was performed using SPSS software, version 17.0 for Windows.

\section{Results}

\section{Patient enrollment and characteristics}

The study flow diagram is shown in Fig. 1. A total of 80 patients completed the study. No significant differences between the two groups were found in terms of the clinical characteristics, including gender, age, body mass index, surgical procedure type, duration of aortic cross clamping, $\mathrm{CPB}$, and anesthesia maintenance $(p>0.05)$ (Table 1).

\section{Hemodynamic parameters}

In comparison to $T_{0}$, the mean arterial blood pressure was decreased at $\mathrm{T}_{1}(p<0.001)$ and increased at $\mathrm{T}_{4,6}$ $(p=0.005$ and $p=0.041)$ in group $C$, while it was decreased at $\mathrm{T}_{1,3} \quad(p<0.001$ and $p=0.021)$ and increased at $\mathrm{T}_{4-6}(p=0.002, p=0.002$, and $p=0.006)$ in group $\mathrm{S}$. The heart rate was significantly decreased at $\mathrm{T}_{1}$ and increased at $\mathrm{T}_{2-6}$ in both groups $(p<0.001)$. There were no differences in hemodynamic variables (mean arterial blood pressure and heart rate) at any time points $(p>0.05)$ between these two groups (Table 2). 


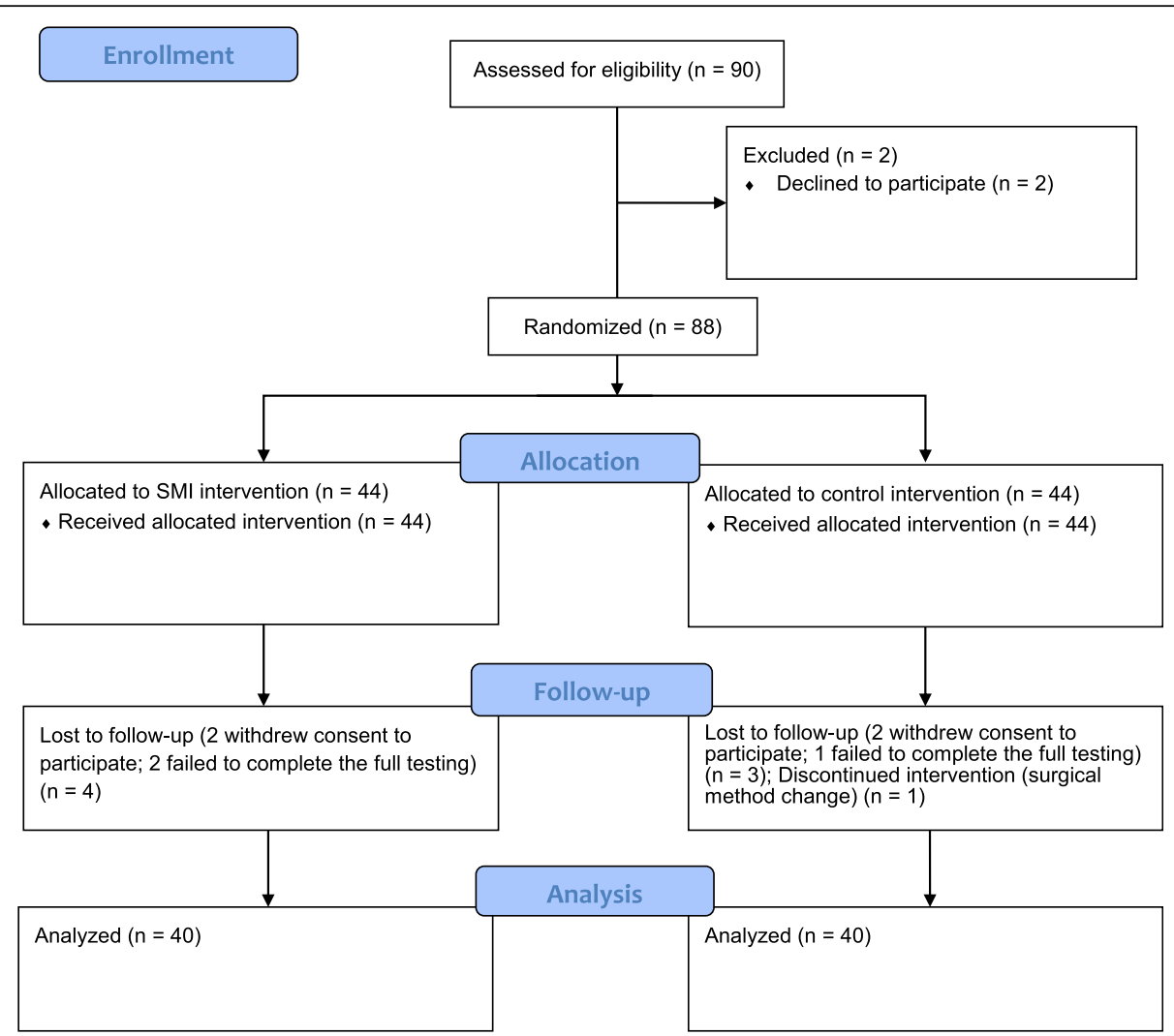

Fig. 1 CONSORT 2010 Flow Diagram

\section{Blood gas analysis}

Table 3 shows the blood gas parameters. Compared to the baseline values at $\mathrm{T}_{0}$, the levels of $\mathrm{S}_{\mathrm{J}} \mathrm{vO}_{2}$ and $\mathrm{P}_{\mathrm{J}} \mathrm{VO}_{2}$ were increased significantly at $\mathrm{T}_{2}(p=0.001$ and $p<0.001)$ in group $\mathrm{C}$ and $\mathrm{T}_{1-2}(p<0.001)$ in group $\mathrm{S}$; the values were much higher in group $\mathrm{S}$ at $\mathrm{T}_{1-3}$ than in group $\mathrm{C}$ $(p<0.001)$ (Fig. 2). The levels of Lacjv were increased at $\mathrm{T}_{1-4}$ (group C: $p<0.001, p<0.001, p<0.001$, and $p=0.003$ and group S: $p<0.001, p<0.001, p<0.001$, and $p=0.002$ ) and decreased at $\mathrm{T}_{6}$ (group C: $p=0.003$;

Table 1 Clinical Characteristics of Patients $(n=40$ in Each Group)

\begin{tabular}{lll}
\hline & Group C & Group S \\
\hline Gender (M/F) & $23 / 17$ & $22 / 18$ \\
Age $(\mathrm{yr})$ & $55 \pm 10$ & $58 \pm 9$ \\
Body mass index (kg/m2) & $23.0 \pm 2.8$ & $24.2 \pm 2.4$ \\
Valve replacement(n) & & \\
$\quad$ single valve replacement & 24 & 26 \\
$\quad$ double valve replacement & 16 & 14 \\
Duration of ACC (min) & $89 \pm 21$ & $86 \pm 20$ \\
Duration ofCPB(min) & $116 \pm 22$ & $111 \pm 24$ \\
Duration of anesthesiamaintenance (min) & $247 \pm 33$ & $239 \pm 29$ \\
\hline
\end{tabular}

$A C C$ aortic cross clamp, $C P B$ cardiopulmonary bypass

Data are presented as mean $\pm S D$, or numbers group S: $p=0.001$ ) in both groups, compared with $\mathrm{T}_{0}$; however the level at $\mathrm{T}_{4}$ in group $\mathrm{S}$ was lower than that in group $C(p<0.001)$ (Fig. 2). The levels of hemoglobin and hematocrit were lower at $\mathrm{T}_{1-6}$ than at $\mathrm{T}_{0}$ $(p<0.001)$, but no differences were found between the two groups $(p>0.05)$.

\section{Concentrations of Ngb, HIF-1a, and NSE}

Table 4 shows the serum levels of Ngb, HIF- $1 \alpha$, and NSE in both groups. Compared with $\mathrm{T}_{0}$, the levels of serum Ngb in group $\mathrm{C}$ were significantly decreased at $\mathrm{T}_{1-2}(p<0.001$ and $p=0.004)$ and significantly increased at $\mathrm{T}_{3-6}(p<0.001)$, with two peaks at $\mathrm{T}_{3}$ and $\mathrm{T}_{6}$, respectively; while the levels in group $\mathrm{S}$ were significantly decreased at $\mathrm{T}_{1-2}(p<0.001)$ and significantly increased at $\mathrm{T}_{4-6}(p=0.023, p<0.001$ and $p<0.001)$, with the highest levels at $\mathrm{T}_{6}$. The levels of serum HIF-1 $\alpha$ were increased at $\mathrm{T}_{1-4}$ and had peaks at $\mathrm{T}_{2}$ in both groups (group $\mathrm{C}$ : $p<0.001, p<0.001, p<0.001$, and $p=0.001$; group $\mathrm{S}$ : $p=0.001, p<0.001, p<0.001$, and $p=0.023)$. The serum NSE levels in both groups were significantly increased at $\mathrm{T}_{1-6} \quad(p<0.001)$. The serum levels of $\mathrm{Ngb}$ at $\mathrm{T}_{3}$ $(p<0.001)$, HIF- $1 \alpha$ at $\mathrm{T}_{1-3}(p<0.001)$, and NSE at $\mathrm{T}_{3-4,6}$ $(p<0.001, p=0.002$, and $p<0.001)$ were lower in group $\mathrm{S}$ than in group $\mathrm{C}$ (Fig. 3). 
Table 2 MAP and HR ( $n=40$ in Each Group)

\begin{tabular}{|c|c|c|c|c|c|c|c|c|}
\hline & Group & $\mathrm{T}_{0}$ & $\mathrm{~T}_{1}$ & $\mathrm{~T}_{2}$ & $T_{3}$ & $\mathrm{~T}_{4}$ & $T_{5}$ & $\mathrm{~T}_{6}$ \\
\hline MAP & C & $73 \pm 10$ & $60 \pm 6^{*}$ & $71 \pm 9$ & $71 \pm 8$ & $83 \pm 8^{*}$ & $80 \pm 9$ & $80 \pm 9^{\dagger}$ \\
\hline (mm Hg) & S & $74 \pm 7$ & $62 \pm 6^{*}$ & $71 \pm 8$ & $69 \pm 5^{\dagger}$ & $81 \pm 9^{*}$ & $83 \pm 9^{*}$ & $80 \pm 6^{*}$ \\
\hline $\mathrm{HR}$ & C & $64 \pm 13$ & $0^{*}$ & $86 \pm 10^{*}$ & $91 \pm 11^{*}$ & $81 \pm 9^{*}$ & $85 \pm 7^{*}$ & $80 \pm 11^{\prime}$ \\
\hline (bpm/min) & S & $62 \pm 10$ & $0^{*}$ & $88 \pm 10^{*}$ & $93 \pm 9^{*}$ & $83 \pm 11^{*}$ & $85 \pm 7^{*}$ & $81 \pm 10^{*}$ \\
\hline
\end{tabular}

$T_{0}, 30$ min after the induction; $T_{1}$, immediately after temperature rewarmed to $36^{\circ} \mathrm{C}_{;} \mathrm{T}_{2}$, end of cardiac surgery; $\mathrm{T}_{3-6}, 6 \mathrm{~h}, 24 \mathrm{~h}, 48 \mathrm{~h}, 72 \mathrm{~h}$ after $\mathrm{CPB}$

Data are expressed as mean \pm SD

${ }^{*} p<0.01$ vs. $\mathbf{T}_{\mathbf{0}}$.† $p<0.05$ vs. $\mathbf{T}_{\mathbf{0}}$

\section{MoCA-BJ analysis}

Compared to preoperative values at 3 days before surgery, the MoCA-BJ scores were decreased at 3 and 7 days after surgery in both groups (group C: $p<0.001$; group S: $p<0.001, p=0.001)$. The MoCA-BJ scores of group $S$ were higher than those in group $C$ at 3 and 7 days after surgery $(p<0.001)$ (Fig. 4). The scores of Clock, Naming, Memory, Serial 7, and Sentence rep in group $\mathrm{C}(p=0.025, p<0.001, p<0.001, p<0.001$ and $p=0.015)$ and the score of Memory in group $\mathrm{S}$ $(p=0.012)$ were lower than the preoperative baseline values at 3 days after surgery. Compared to group $C$, the scores of Cube, Memory, Serial 7, and Sentence rep were elevated at 3 days after surgery in group $\mathrm{S}(p=0.005$, $p=0.005, p=0.008$, and $p<0.001$ ) (Fig. 5).

\section{Discussion}

Recent technological advances have contributed to an increasingly lower rate of clinically evident complications, but POCD remains an important clinical problem associated with cardiac surgery $[12,13]$. Its manifestations may include impairment in visuospatial and executive functions, naming, attention, language, delayed recall (memory), and orientation [14]. Presently, the MoCA and the Mini-Mental State Examination (MMSE) are the most commonly used neuropsychological tests for POCD. As a simple cognitive screening tool, the
MoCA-BJ was used in this study to balance the influences of various ages and education levels; [15] and its sensitivity and specificity are better than those of the MMSE [16, 17]. As shown in this study, the total MoCA-BJ scores were significantly lower at 3 and 7 days after surgery in patients receiving cardiac surgery in group $\mathrm{C}$, and the scores basically recovered to baseline values at 1 month after surgery, suggesting that the patients suffered from POCD in the early but not the late stage after cardiac surgery. The results also showed that several cognitive domains, especially memory, were badly impaired; these results were identical to previous ones [18, 19]. For example, Yu et al. [16] have reported that among all the cognitive subdomains, delayed recall (Memory) was shown to be the best index to differentiate POCD from the normal controls. Similarly, Jones et al. [20] have reported that the severity of heart/circulation problems independently contributed to a worse delayed recall (Memory) performance. Our results showed that the Memory scores were lower than the baseline values at 3 days after surgery in both groups, but the scores in group $\mathrm{S}$ were improved after SMI administration. In addition, changes in the Clock, Naming, Serial 7, and Sentence rep scores were similar as the delayed recall evaluation, which were all lower than the preoperative baselines values.

Table 3 Blood Gas Parameters ( $n=40$ in Each Group)

\begin{tabular}{|c|c|c|c|c|c|c|c|c|}
\hline & Group & $\mathrm{T}_{0}$ & $\mathrm{~T}_{1}$ & $\mathrm{~T}_{2}$ & $T_{3}$ & $\mathrm{~T}_{4}$ & $\mathrm{~T}_{5}$ & $T_{6}$ \\
\hline SJ vO2 & C & $58.2 \pm 12.6$ & $48.4 \pm 4.7^{*}$ & $64.3 \pm 8.0^{*}$ & $54.7 \pm 8.9$ & $54.8 \pm 5.4$ & $50.7 \pm 6.1^{*}$ & $53.3 \pm 8.7$ \\
\hline (\%) & S & $57.7 \pm 8.8$ & $70.5 \pm 12.0^{* \neq}$ & $75.8 \pm 7.4^{* \neq}$ & $59.9 \pm 4.6^{\ddagger}$ & $56.1 \pm 3.8$ & $52.1 \pm 6.0^{*}$ & $50.8 \pm 4.4^{*}$ \\
\hline PJ VO2 & C & $33.8 \pm 8.1$ & $29.5 \pm 2.8^{*}$ & $40.1 \pm 6.0^{*}$ & $32.1 \pm 5.1$ & $31.0 \pm 2.5^{\dagger}$ & $28.3 \pm 3.0^{*}$ & $29.7 \pm 4.2^{\dagger}$ \\
\hline$(\mathrm{mmHg})$ & S & $34.1 \pm 3.9$ & $45.7 \pm 11.8^{* \neq}$ & $50.4 \pm 8.0^{* \neq}$ & $34.6 \pm 4.0^{\ddagger}$ & $30.5 \pm 2.1^{*}$ & $28.8 \pm 3.1^{*}$ & $28.6 \pm 2.5^{*}$ \\
\hline Lacjv & C & $1.1 \pm 0.5$ & $1.7 \pm 0.7^{*}$ & $1.9 \pm 1.0^{*}$ & $2.1 \pm 1.0^{*}$ & $2.0 \pm 0.8^{*}$ & $1.0 \pm 0.3$ & $0.8 \pm 0.3^{*}$ \\
\hline$(\mathrm{mmol} / \mathrm{L})$ & S & $1.1 \pm 0.5$ & $1.7 \pm 0.7^{*}$ & $1.9 \pm 0.8^{*}$ & $1.9 \pm 0.8^{*}$ & $1.4 \pm 0.6^{* \neq}$ & $1.0 \pm 0.3$ & $0.8 \pm 0.3^{*}$ \\
\hline $\mathrm{Hb}$ & C & $12.8 \pm 1.4$ & $8.1 \pm 0.9^{*}$ & $9.5 \pm 1.1^{*}$ & $10.5 \pm 1.3^{*}$ & $11.1 \pm 1.3^{*}$ & $9.9 \pm 1.1^{*}$ & $9.8 \pm 1.1^{*}$ \\
\hline$(\mathrm{g} / \mathrm{dL})$ & S & $13.0 \pm 1.1$ & $8.1 \pm 0.7^{*}$ & $9.6 \pm 1.0^{*}$ & $10.3 \pm 0.9^{*}$ & $11.3 \pm 0.9^{*}$ & $10.1 \pm 1.3^{*}$ & $10.2 \pm 1.4^{*}$ \\
\hline $\mathrm{HCT}$ & C & $37.8 \pm 4.1$ & $24.0 \pm 2.8^{*}$ & $28.0 \pm 3.1^{*}$ & $30.9 \pm 3.2^{*}$ & $32.5 \pm 3.9^{*}$ & $29.2 \pm 3.3^{*}$ & $28.7 \pm 3.1^{*}$ \\
\hline (\%) & S & $38.1 \pm 3.3$ & $24.0 \pm 1.9^{*}$ & $28.3 \pm 3.0^{*}$ & $30.4 \pm 2.6^{*}$ & $33.2 \pm 2.7^{*}$ & $29.7 \pm 3.9^{*}$ & $30.1 \pm 4.0^{*}$ \\
\hline
\end{tabular}

$T_{0}, 30$ min after the induction; $T_{1}$, immediately after temperature rewarmed to $36{ }^{\circ} C_{;} T_{2}$, end of cardiac surgery; $T_{3-6}, 6 \mathrm{~h}, 24 \mathrm{~h}, 48 \mathrm{~h}, 72 \mathrm{~h}$ after $\mathrm{CPB}$ Data are expressed as mean $\pm \mathrm{SD}$

${ }^{*} p<0.01$ vs. $\mathbf{T}_{\mathbf{0}} . \dagger p<0.05$ vs. $\mathbf{T}_{\mathbf{0}} . \neq p<0.01$ vs. group $\mathrm{C}$ 

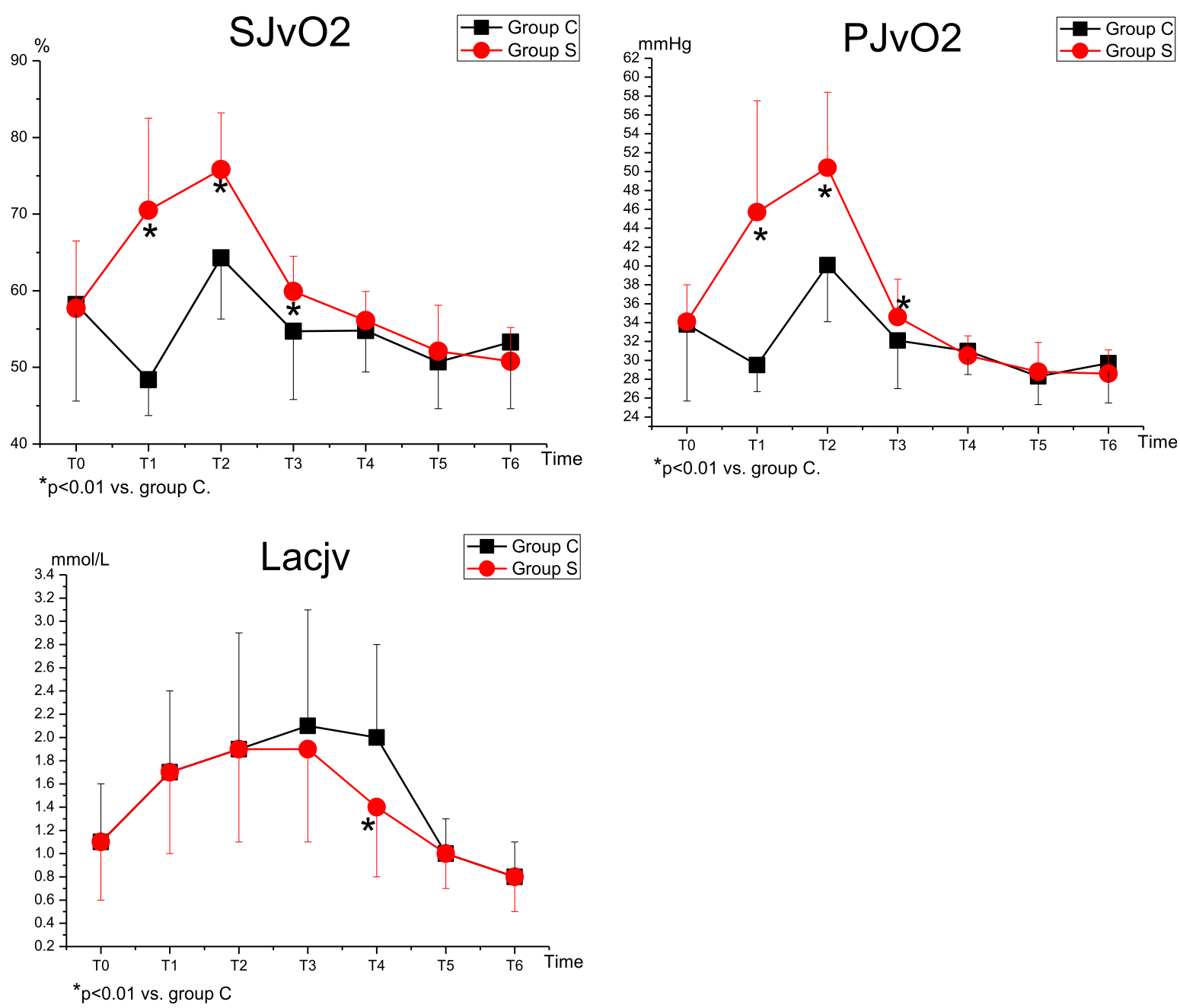

$* \mathrm{p}<0.01$ vs. group C.

Fig. 2 Blood Gas Parameters

Table 4 Serum Levels of Ngb, HIF-1a and NSE( $n=40$ in Each Group)

\begin{tabular}{lllllllll}
\hline & Group & $\mathrm{T}_{0}$ & $\mathrm{~T}_{1}$ & $\mathrm{~T}_{2}$ & $\mathrm{~T}_{3}$ & $\mathrm{~T}_{4}$ & $\mathrm{~T}_{5}$ \\
\hline $\mathrm{Ngb}$ & $\mathrm{C}$ & $1.23 \pm 0.42$ & $0.53 \pm 0.19^{*}$ & $0.93 \pm 0.43^{*}$ & $2.83 \pm 1.14^{*}$ & $1.89 \pm 0.77^{*}$ & $1.92 \pm 0.83^{*}$ & $2.33 \pm 0.74^{*}$ \\
$(\mathrm{ng} / \mathrm{mL})$ & $\mathrm{S}$ & $1.35 \pm 0.39$ & $0.61 \pm 0.23^{*}$ & $0.93 \pm 0.32^{*}$ & $1.20 \pm 0.61^{\ddagger}$ & $1.62 \pm 0.59^{\dagger}$ & $1.94 \pm 0.80^{*}$ & $2.35 \pm 0.83^{*}$ \\
$\mathrm{HIF-1a}$ & $\mathrm{C}$ & $2.01 \pm 0.55$ & $4.54 \pm 1.38^{*}$ & $10.98 \pm 2.55^{*}$ & $6.56 \pm 2.06^{*}$ & $2.48 \pm 0.99^{*}$ & $2.04 \pm 0.62$ & $2.33 \pm 1.12$ \\
$(\mathrm{ng} / \mathrm{mL})$ & $\mathrm{S}$ & $1.93 \pm 0.68$ & $2.37 \pm 1.04^{*}$ & $9.11 \pm 1.49^{*} \neq$ & $4.69 \pm 2.01^{*} \neq$ & $2.36 \pm 1.30^{\dagger}$ & $2.15 \pm 0.90$ & $1.98 \pm 0.77$ \\
$\mathrm{NSE}$ & $\mathrm{C}$ & $5.05 \pm 1.21$ & $18.47 \pm 5.72^{*}$ & $34.93 \pm 12.33^{*}$ & $40.77 \pm 15.73^{*}$ & $14.25 \pm 5.67^{*}$ & $9.54 \pm 3.50^{*}$ & $12.27 \pm 5.76^{*}$ \\
$(\mathrm{ng} / \mathrm{mL})$ & $\mathrm{S}$ & $5.28 \pm 1.35$ & $17.67 \pm 5.51^{*}$ & $33.82 \pm 12.78^{*}$ & $27.96 \pm 6.53^{* \neq}$ & $10.51 \pm 4.94^{*}$ & $8.25 \pm 3.61^{*}$ & $6.44 \pm 1.35^{*}$
\end{tabular}

$T_{0}, 30$ min after the induction; $T_{1}$, immediately after temperature rewarmed to $36{ }^{\circ} \mathrm{C}_{;} \mathrm{T}_{2}$, end of cardiac surgery; $T_{3-6}, 6 \mathrm{~h}, 24 \mathrm{~h}, 48 \mathrm{~h}, 72 \mathrm{~h}$ after $\mathrm{CPB}$ Data are expressed as mean $\pm \mathrm{SD}$

${ }^{*} p<0.01$ vs. $\mathrm{T}_{0} . \dagger p<0.05$ vs. $\mathrm{T}_{0} . \neq p<0.01$ vs. group $\mathrm{C}$ 


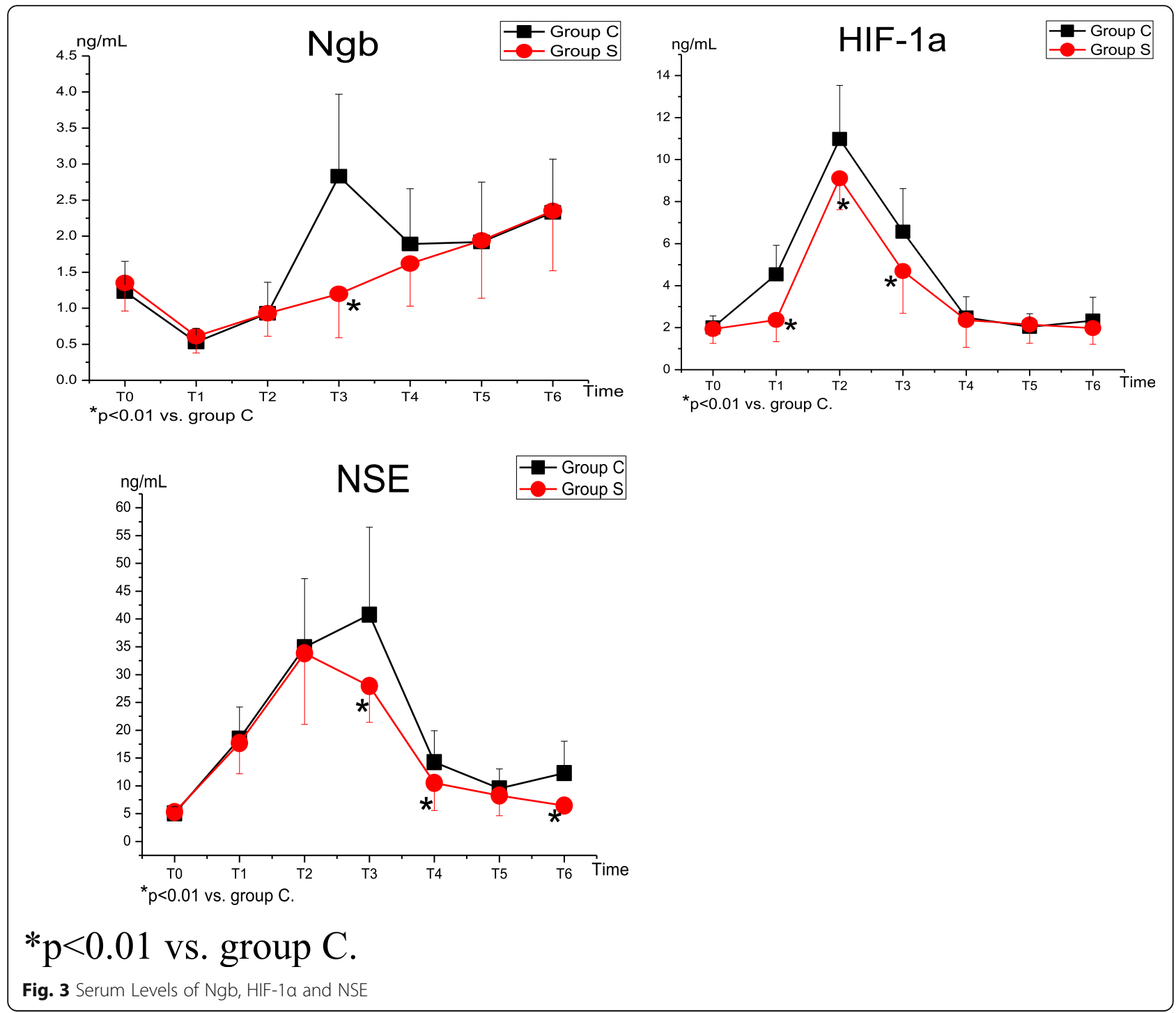

Though the cognitive damages after cardiac surgery have been well described, the exact mechanisms involved have not been elucidated. Zheng et al. [21] have reported an association between decreased regional cerebral oxygen saturation $\left(\mathrm{rScO}_{2}\right)$, desaturation, and POCD in adult patients receiving cardiac surgery. The blood flow of the internal jugular vein bulbar is mainly from the cerebral hemisphere, and the levels of $\mathrm{S}_{\mathrm{J}} \mathrm{VO}_{2}$ and $\mathrm{P}_{\mathrm{J}} \mathrm{vO}_{2}$ can indirectly reflect $\mathrm{rScO}_{2}[22,23]$. As shown in our study, compared to the baseline values, the levels of $\mathrm{S}_{\mathrm{J}} \mathrm{VO} 2$ and $\mathrm{P}_{\mathrm{J}} \mathrm{VO} 2$ were significantly decreased and the levels of Lacjv were increased in patients undergoing CPB, suggesting that cerebral anoxia may at least partly contribute to POCD.

Ngb, a novel neuroprotective protein, affords protection against hypoxia/ischemia and oxidative stress-induced injury in the nervous system. Ngb overexpression enhances cell survival under conditions of anoxia or oxygen and glucose deprivation [24], and it protects neurons against cerebral ischemia-reperfusion injury [25]. Previous data have implied that the upregulated expression of Ngb could be an endogenous compensatory or protective mechanism in response to sublethal hypoxic/ischemic insults to brain neurons, and Barzo et al. [26] have reported that a predominantly vasogenic edema formation occurred immediately after brain injury and a more widespread and slower cytotoxic edema formation resulted later, which may lead to two peaks of Ngb expression following brain injury. Furthermore, recent studies have found that the Ngb levels are increased in early and moderately advanced Alzheimer's disease subjects [27]. These findings may explain the results uncovered in our study.

HIF-1 $\alpha$ has emerged as a critical oxygen-sensitive transcription factor that orchestrates the body's protective response to hypoxia and can protect organs against acute ischemic injury [28]. Moreover, it has been 


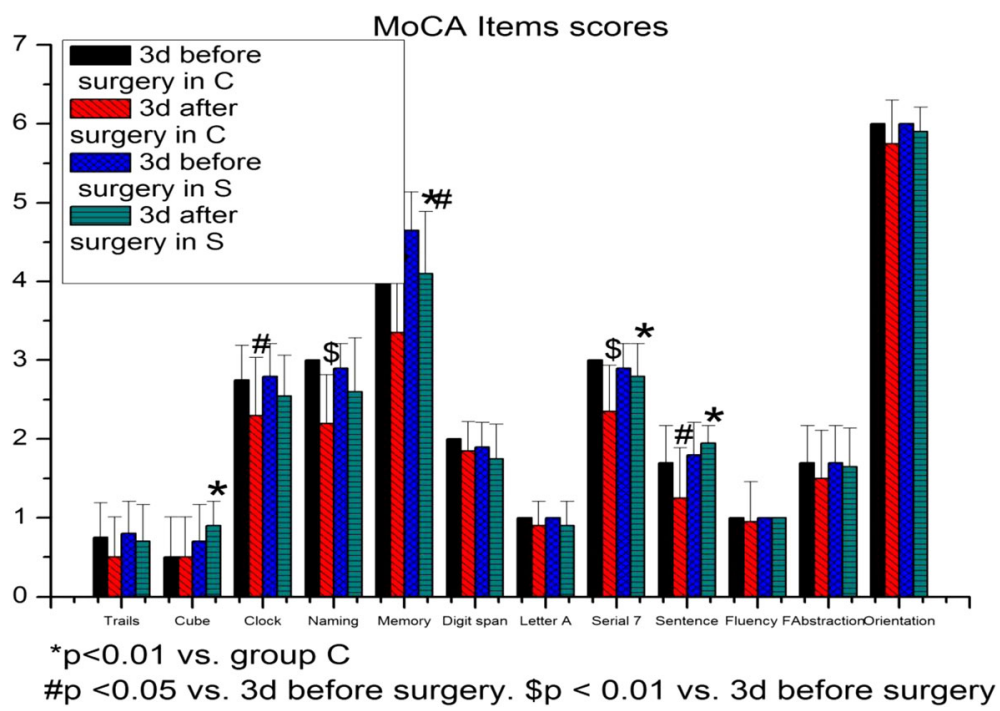

Fig. 5 MoCA-BJ Items scores

recently documented that the expression of HIF- $1 \alpha$ under hypoxia has protective effects on astrocytes, thus playing an important role in cerebral protection [29]. Its protective effects also have been proven in a model of cultured cortical neurons exposed to moderate hypoxia $[30,31]$. As shown in our study, the serum HIF-1 $\alpha$ level began to increase before the Ngb level. The role of HIF- $1 \alpha$ in the regulation of oxygen homeostasis in tissue may be correlated with Ngb expression [32]. Additionally, a recent study has demonstrated that HIF- $1 \alpha$ contributes to the upregulation of Ngb expression under hypoxic conditions in mice [33]. However, further studies are necessary to elucidate the exact mechanisms of HIF- $1 \alpha$ in Ngb regulation under hypoxic and other pathological conditions.

NSE, which was originally described by Moore and McGregor in 1965, [34] has been considered as a traditional marker to assess neuronal damage; [35] however, clinical trials have shown controversial results regarding the correlation between cognitive dysfunction and the circulating NSE level. Some studies have found a correlation between the NSE level and the clinical outcome of neurocognitive dysfunction, [36-38] but others have failed to do so $[39,40]$. In our study, the serum NSE levels were significantly increased after $\mathrm{CPB}$. Therefore, NSE may be an indicative parameter for POCD.

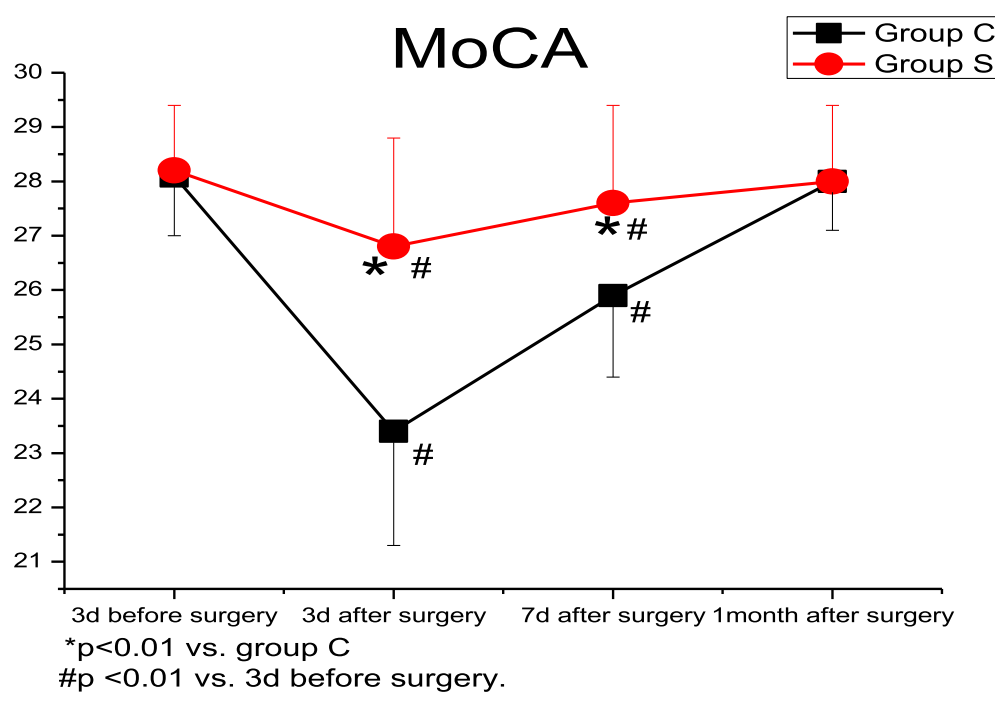

Fig. 4 Total MoCA-BJ scores 
SMI, a traditional Chinese herbal medicine, is widely used in mainland China for the treatment of cardio/cerebrovascular disorders and as an adjunct therapy to tumor chemotherapy [41]. The active component of SMI is radix ginseng rubra, which contains Ginsenoside Rg3 and Ginsenoside Rb1. The protective effects of Ginsenoside $\mathrm{Rb} 1$ have been well proven in various models of cerebral ischemia-reperfusion injury [42, 43]. Its possible mechanism of the protective effect on the central nervous system involves calcium channel blockade, estrogen-like action, and antiperoxidation, which may inhibit cerebral nerve cell apoptosis and ameliorate mitochondrial dysfunction, etc [44]. Hence, we hypothesized that treatment with SMI might present beneficial effects against reperfusion injury and improve cognitive function after cardiac valve replacement under $\mathrm{CPB}$. As shown in our study, even though the MoCA-BJ score in group $\mathrm{S}$ was decreased at 3 days after surgery but was still improved as compared to group $\mathrm{C}$ at the early stage after CPB, SMI treatment increased the levels of $\mathrm{S}_{\mathrm{J}} \mathrm{VO}_{2}$ and $\mathrm{P}_{\mathrm{J}} \mathrm{vO}_{2}$ as well as decreased the serum Ngb, HIF- $1 \alpha$, and NSE levels at different time points. These data implied that SMI may attenuate cerebral anoxia and neuronal damage, subsequently improving cognitive function and reducing the incidence of POCD.

Several limitations of this study should be noted. First, enrollment of patients did not consider the traditional Chinese medicine syndromes, and the lack of traditional Chinese medicine syndrome diagnosis during patient enrolment was another potential source of selection bias. Second, whether SMI exerts protective effects by improving cerebral oxygenation directly or by other implied mechanisms should be investigated in future studies. Finally, the optimal dosage of SMI and its main effective ingredient were not determined in the current study. Our future studies will address these issues.

\section{Conclusions}

In conclusion, cognitive function is impaired postoperatively in patients undergoing cardiac surgery with $\mathrm{CPB}$. The novel biomarkers Ngb, HIF- $1 \alpha$, and NSE could serve as early indicators for POCD. Treatment with SMI, a traditional Chinese medicine, decreases the levels of serum Ngb, HIF- $1 \alpha$, and NSE, thus improving cognitive function.

\section{Abbreviations}

CCU: Coronary Care Unit; CPB: Cardiopulmonary bypass; HIF-1a: Hypoxiainducible factor-1a; MoCA-BJ: Beijing version of the Montreal Cognitive Assessment; Ngb: Neuroglobin; NSE: Neuron-specific enolase; POCD: Postoperative cognitive dysfunction; $\mathrm{rSCO}_{2}$ : Regional cerebral oxygen saturation; SMI: Shenmai Injection
}

\section{Funding}

The present study was granted by Wenzhou Municipal Science and Technology Bureau (No. H20100010).

\section{Availability of data and materials}

The datasets generated and/or analyzed during the current study are not publicly available due to them containing information that could compromise research participant privacy, but might be made available from the corresponding author on reasonable request.

\section{Authors' contributions}

LNL and LRW designed this study and wrote the manuscript. CL and LLL performed the experiments. QZ1 collected all data. QZ2 and FFC assisted with data analysis. All the authors approved the final version of the manuscript. $\mathrm{CL}$ and LRW were co-first authors and contributed equally to this study.

\section{Ethics approval and consent to participate}

This study was approved by the ethics committee of the First Affiliated Hospital of Wenzhou Medical University and written informed consent was obtained from all patients according to international guidelines.

\section{Consent for publication}

Not applicable.

\section{Competing interests}

The authors declare that they have no competing interests.

\section{Publisher's Note}

Springer Nature remains neutral with regard to jurisdictional claims in published maps and institutional affiliations.

\section{Author details}

${ }^{1}$ Department of Anesthesiology, The First Affiliated Hospital of Wenzhou Medical University, Wenzhou, Zhejiang Province, China. ${ }^{2}$ Wenzhou People's Hospital, Wenzhou, Zhejiang Province, China.

Received: 20 March 2018 Accepted: 24 September 2018

Published online: 11 October 2018

\section{References}

1. Tonkovic D, Marinic DK, Baronica R, Oberhofer D, Pavlovic DB, Peric M. Postoperative mental disorders in cardiovascular surgery. Acta Med Croatica. 2012;66:67-72.

2. Hartholt KA, van der Cammen TJ, Klimek M. Postoperative cognitive dysfunction in geriatric patients. Z Gerontol Geriatr. 2012;45:411-6. https:// doi.org/10.1007/s00391-012-0326-2.

3. Djaiani G, Katznelson R, Fedorko L, Rao V, Green R, Carroll J, Katski J. Early benefit of preserved cognitive function is not sustained at one-year after cardiac surgery: a longitudinal follow-up of the randomized controlled trial. Can J Anaesth. 2012;59:449-55. https://doi.org/10.1007/s12630-012-9675-y.

4. Papadopoulos G, Karanikolas M, Liarmakopoulou A, Papathanakos G, Korre M, Beris A. Cerebral oximetry and cognitive dysfunction in elderly patients undergoing surgery for hip fractures: a prospective observational study. Open Orthop J. 2012;6:400-5. https://doi.org/10.2174/1874325001206010400.

5. Hota KB, Hota SK, Srivastava RB, Singh SB. Neuroglobin regulates hypoxic response of neuronal cells through Hif-1alpha- and Nrf2-mediated mechanism. J Cereb Blood Flow Metab. 2012 Jun;32(6):1046-60. https://doi.org/10.1038/jcbfm.2012.21.

6. Yildirim AO, Eroglu M, Kaldirim U, Eyi YE, Simsek K, Durusu M, Yamanel L, Arziman I, Tuncer SK, Toygar M, Balkan A, Cayci T, Demirbas S, Oter S, Bilgi C. Serum neuron-specific enolase and S-100beta levels as prognostic followup markers for oxygen administered carbon monoxide intoxication cases. Indian J Biochem Biophys. 2015;52:29-33.

7. Wang L, Wang W, Zhao X, Jin L, Bai Y, Yao H, Zhuo O, Lin L. Effect of Shenmai injection, a traditional Chinese medicine, on pulmonary dysfunction after tourniquet-induced limb ischemia-reperfusion. J Trauma. 2011;71:893-7. https://doi.org/10.1097/TA.0b013e318205e279.

8. Lin L, Wang L, Chen F, Hu M, Miao J, Wang J. Effect and significance of Shenmai injection on value of vascular endothelial active factors of heart valve replacement patients. Zhongguo Zhong Yao Za Zhi. 2009;34:1155-8.

9. Lin LN, Zhang SG, Wang WT, Xi JH, Qiu XX, Dai YY. Effect of Shenmai injection on expression and activity of heme oxygenase-1 in reperfusion injury after pulmonary ischemia in rabbits. Zhongguo Zhong yao za zhi. 2008:33:296-9.

10. Chen FF, Lin LN, Miao JX. Protective effect of Shenmai injection on lung injury induced by cardiac pulmonary bypass. Zhongguo Zhong Xi Yi Jie He Za Zhi. 2009:29:414-7. 
11. Cheng CW, Wu TX, Shang HC, Li YP, Altman DG, Moher D, Bian ZX, Group C-CF. CONSORT extension for Chinese herbal medicine formulas 2017: recommendations, explanation, and elaboration (traditional Chinese version). Ann Intern Med. 2017;167:W7-W20. https://doi.org/10.7326/ IsTranslatedFrom_M17-2977_1.

12. Schwarz N, Schonburg M, Kastaun S, Gerriets T, Kaps M. Cognitive deterioration after cardiosurgery. Nervenarzt. 2011;82(190):192-7. https://doi. org/10.1007/s00115-010-3116-3

13. Lombard FW, Mathew JP. Neurocognitive dysfunction following cardiac surgery. Semin Cardiothorac Vasc Anesth. 2010;14:102-10. https://doi.org/10. $1177 / 1089253210371519$

14. Nie K, Zhang Y, Wang L, Zhao J, Huang Z, Gan R, Li S, Wang L. A pilot study of psychometric properties of the Beijing version of Montreal cognitive assessment in patients with idiopathic Parkinson's disease in China. J Clin Neurosci. 2012;19:1497-500. https://doi.org/10.1016/j.jocn.2011.11.039.

15. Nasreddine ZS. Montreal Cognitive Assessment. https://www.mocatest.org/. 2003/2012-10-4

16. Yu J, Li J, Huang X. The Beijing version of the Montreal cognitive assessment as a brief screening tool for mild cognitive impairment: a community-based study. BMC Psychiatry. 2012;12:156. https://doi.org/10.1186/1471-244X-12-156.

17. Tan JP, Li N, Gao J, Wang LN, Zhao YM, Yu BC, Du W, Zhang WJ, Cui LQ, Wang QS, Li JJ, Yang JS, Yu JM, Xia XN, Zhou PY. Optimal cutoff scores for dementia and mild cognitive impairment of the Montreal cognitive assessment among elderly and oldest-old Chinese population. J Alzheimers Dis. 2015;43:1403-12. https://doi.org/10.3233/JAD-141278.

18. Burkhart CS, Steiner LA. Can postoperative cognitive dysfunction be avoided? Hosp Pract (1995). 2012:40:214-23. https://doi.org/10.3810/hp.2012.02.962.

19. An LN, Yue Y, Guo WZ, Miao YL, Mi WD, Zhang H, Lei ZL, Han SJ, Dong L. Surgical trauma induces iron accumulation and oxidative stress in a rodent model of postoperative cognitive dysfunction. Biol Trace Elem Res. 2013; 151:277-83. https://doi.org/10.1007/s12011-012-9564-9.

20. Jones JD, Malaty I, Price CC, Okun MS, Bowers D. Health comorbidities and cognition in 1948 patients with idiopathic Parkinson's disease. Parkinsonism Relat Disord. 2012;18:1073-8. https://doi.org/10.1016/j.parkreldis.2012.06.004.

21. Zheng F, Sheinberg R, Yee MS, Ono M, Zheng Y, Hogue CW. Cerebral nearinfrared spectroscopy monitoring and neurologic outcomes in adult cardiac surgery patients: a systematic review. Anesth Analg. 2013;116:663-76. https://doi.org/10.1213/ANE.0b013e318277a255.

22. Walther T, Dhein S, Ullmann C, Schneider K, Bilz T, Rastan A, Garbade J, Falk V, Emrich FC, Muth P, Mohr FW, Kostelka M. Cerebral protection during controlled hypoperfusion in a piglet model: comparison of moderate $\left(25^{\circ} \mathrm{C}\right)$ versus deep $\left(18^{\circ} \mathrm{C}\right)$ hypothermia at various flow rates using intraoperative measurements and ex vivo investigation. Thorac Cardiovasc Surg. 2013;61: 546-52. https://doi.org/10.1055/s-0032-1324710.

23. Sari A, Yamashita S, Ohosita S, Ogasahara H, Yamada K, Yonei A, Yokota K. Cerebrovascular reactivity to $\mathrm{CO} 2$ in patients with hepatic or septic encephalopathy. Resuscitation. 1990;19:125-34.

24. Fordel E, Thijs L, Martinet W, Schrijvers D, Moens L, Dewilde S. Anoxia or oxygen and glucose deprivation in SH-SY5Y cells: a step closer to the unraveling of neuroglobin and cytoglobin functions. Gene. 2007;398:114-22.

25. Li SQ, Li WB, Zhang M, Wu YZ, Hu YY. The role of neuroglobin in the neuroprotection of limb ischemic preconditioning in rats. Mol Neurobiol. 2013:47:197-208. https://doi.org/10.1007/s12035-012-8373-7.

26. Barzo P, Marmarou A, Fatouros P, Hayasaki K, Corwin F. Biphasic pathophysiological response of vasogenic and cellular edema in traumatic brain swelling. Acta Neurochir Suppl. 1997;70:119-22.

27. Sun F, Mao X, Xie L, Greenberg DA, Jin K. Neuroglobin protein is upregulated in Alzheimer's disease. J Alzheimers Dis. 2013;36:659-63. https://doi.org/10.3233/JAD-130323.

28. Ong SG, Hausenloy DJ. Hypoxia-inducible factor as a therapeutic target for cardioprotection. Pharmacol Ther. 2012;136:69-81. https://doi.org/10.1016/j. pharmthera.2012.07.005

29. Badawi $Y$, Ramamoorthy $\mathrm{P}$, Shi H. Hypoxia-inducible factor 1 protects hypoxic astrocytes against glutamate toxicity. ASN Neuro. 2012;4:231-41. https://doi.org/10.1042/AN20120006.

30. Li D, Bai T, Brorson JR. Adaptation to moderate hypoxia protects cortical neurons against ischemia-reperfusion injury and excitotoxicity independently of HIF-1alpha. Exp Neurol. 2011;230:302-10. https://doi.org/ 10.1016/j.expneurol.2011.05.009.
31. Shao G, Gao CY, Lu GW. Alterations of hypoxia-inducible factor-1 alpha in the hippocampus of mice acutely and repeatedly exposed to hypoxia. Neurosignals. 2005;14:255-61.

32. Di Giulio C, Zara S, Cataldi A, Porzionato A, Pokorski M, De Caro R. Human carotid body HIF and NGB expression during human development and aging. Adv Exp Med Biol 2012;758:265-271. doi: https://doi.org/10.1007/97894-007-4584-1_36.

33. Liu N, Yu Z, Xiang S, Zhao S, Tjarnlund-Wolf A, Xing C, Zhang J, Wang X Transcriptional regulation mechanisms of hypoxia-induced neuroglobin gene expression. Biochem J. 2012;443:153-64. https://doi.org/10.1042/ BJ20111856.

34. Moore BW, McGregor D. Chromatographic and electrophoretic fractionation of soluble proteins of brain and liver. J Biol Chem. 1965;240:1647-53.

35. Giacoppo S, Bramanti P, Barresi M, Celi D, Foti Cuzzola V, Palella E, Marino S. Predictive biomarkers of recovery in traumatic brain injury. Neurocrit Care. 2012;16:470-7. https://doi.org/10.1007/s12028-012-9707-z.

36. Zhang B, Huang Y, Su Z, Wang S, Wang S, Wang J, Wang A, Lai X. Neurological, functional, and biomechanical characteristics after highvelocity behind armor blunt trauma of the spine. J Trauma. 2011;71:1680-8. https://doi.org/10.1097/TA.0b013e318231bce7.

37. Prohl J, Rother J, Kluge S, de Heer G, Liepert J, Bodenburg S, Pawlik K, Kreymann G. Prediction of short-term and long-term outcomes after cardiac arrest: a prospective multivariate approach combining biochemical, clinical, electrophysiological, and neuropsychological investigations. Crit Care Med. 2007;35:1230-7.

38. Ramlawi B, Rudolph JL, Mieno S, Khabbaz K, Sodha NR, Boodhwani M, Levkoff SE, Marcantonio ER, Sellke FW. Serologic markers of brain injury and cognitive function after cardiopulmonary bypass. Ann Surg. 2006;244:593-601.

39. Reinsfelt B, Ricksten SE, Zetterberg H, Blennow K, Freden-Lindqvist J, Westerlind A. Cerebrospinal fluid markers of brain injury, inflammation, and blood-brain barrier dysfunction in cardiac surgery. Ann Thorac Surg. 2012; 94:549-55. https://doi.org/10.1016/j.athoracsur.2012.04.044.

40. McDonagh DL, Mathew JP, White WD, Phillips-Bute B, Laskowitz DT, Podgoreanu MV, Newman MF, Neurologic Outcome Research G. Cognitive function after major noncardiac surgery, apolipoprotein E4 genotype, and biomarkers of brain injury. Anesthesiology. 2010;112:852-9. https://doi.org/ 10.1097/ALN.0b013e3181d31fd7.

41. Lu LY, Zheng GQ, Wang Y. An overview of systematic reviews of shenmai injection for healthcare. Evid Based Complement Alternat Med. 2014;2014: 840650. https://doi.org/10.1155/2014/840650.

42. Zhu J, Jiang Y, Wu L, Lu T, Xu G, Liu X. Suppression of local inflammation contributes to the neuroprotective effect of ginsenoside $\mathrm{Rb} 1$ in rats with cerebral ischemia. Neuroscience. 2012;202:342-51. https://doi.org/10.1016/j. neuroscience.2011.11.070.

43. Yang CX, Liu JX, Sun ZL, Gao XQ, Deng L, Yuan QL. Effects of Ginsenoside $\mathrm{RB} 1$ on neural cell apoptosis and expressions of Bcl-2 and Bax in rats following subjected to cerebral ischemia-reperfusion. Sichuan da xue xue bao Yi xue ban. 2008:39:214-7.

44. Wang WX, Wang W, Chen KJ. Protective effect and mechanism of ginsenosides on central nerve system of animals. Zhongguo Zhong Xi Yi Jie He Za Zhi. 2005;25:89-93.
Ready to submit your research? Choose BMC and benefit from:
- fast, convenient online submission
- thorough peer review by experienced researchers in your field
- rapid publication on acceptance
- support for research data, including large and complex data types
- gold Open Access which fosters wider collaboration and increased citations
- maximum visibility for your research: over $100 \mathrm{M}$ website views per year
At $\mathrm{BMC}$, research is always in progress. 